\title{
Future research and clinical directions in the field of men's mental health: the Madrid declaration
}

\section{Leo Sher ${ }^{1,2}{ }^{*}$, Zoltan Rihmer ${ }^{3}$, Javier Didia-Attas ${ }^{4}$, Jose de Leon $^{5}$, Shih-Ku Lin ${ }^{6,7}$, Carlos Roncero ${ }^{8}$, Nestor Szerman ${ }^{9}$ and Timothy Rice ${ }^{1}$}

1 Icahn School of Medicine at Mount Sinai, New York, NY, USA

2 James J. Peters Veterans' Administration Medical Center, Bronx, NY, USA

${ }^{3}$ Semmelweis University, Budapest, Hungary

${ }^{4}$ Hospital Italiano, Buenos Aires, Argentina

${ }^{5}$ University of Kentucky, Lexington, $K Y, U S A$

${ }^{6}$ Taipei Medical University, Taipei, Taiwan

${ }^{7}$ Psychiatric Center, Taipei City Hospital, Taipei, Taiwan

${ }^{8}$ University Hospital Vall Hebron, Universidad Autónoma de Barcelona, Barcelona, Spain

${ }^{9}$ Complutense University of Madrid, Madrid, Spain

*Correspondence: drleosher@gmail.com;leo.sher@mssm.edu

Edited by:

Frederick Robert Carrick, Carrick Institute for Graduate Studies, USA

Reviewed by:

Susan Elizabeth Esposito, Life University, USA

Linda Mullin Elkins, Life University, USA

Matthew M. Antonucci, Carrick Institute for Graduate Studies, USA

Keywords: mental disorders, men's mental health, alcoholism, substance-related disorders, stress, psychological

The members of the World Federation of Biological Psychiatry's Task Force on Men's Mental Health met in Madrid in September 2014 to discuss the research and clinical directions in the field of Men's Mental Health. Leo Sher, M.D. (USA), Zoltan Rihmer, M.D., Ph.D. (Hungary), Javier DidiaAttas, M.D. (Argentina), Jose de Leon, M.D. (USA), Shih-Ku Lin, M.D. (Taiwan), Carlos Roncero, M.D. (Spain), and Nestor Szerman, M.D. (Spain) participated in the meeting. The following consensus recommendations were made.

\section{HELP-SEEKING BEHAVIOR}

Men seek help less frequently than women $(1,2)$. Young men in particular receive less health care and are more often uninsured (3). Without routine preventative care, risk factors, and warning signs for mental health concerns can go unobserved and unaddressed. Among men, and young men, in particular, masculinity is directly associated with receiving less healthcare and particularly mental health services (1, 4, 5). Research, clinical work, and public health interventions targeting misconceptions among males that a lifestyle involving poor self-care and lack of help seeking is masculine are needed.

\section{IMPULSIVITY}

Men are more impulsive and aggressive than women $(6,7)$. This leads to suicidality
(6-8), substance abuse (9), and aggressive violence and homicidality $(7,10)$. There are defined neural correlates for this association (11). The focus of research and clinical work must be how to continue to further define these neural correlates, how to diagnose and treat impulsivity, and how to reduce access to lethal means.

\section{ALCOHOL AND DRUG ABUSE IN MEN}

There is a consistent and greater male use of alcohol, benzodiazepines, and illegal drugs of abuse $(2,12)$. This is particularly true with alcohol, especially in select cultures, including those of Eastern Europe and the Americas. Patterns of use and behavior additionally diverge. Research and clinical work should be focused on targeted interventions to reduce male substance abuse and its associated disruptive behavior, suicidality, and aggression.

\section{WORK RELATED STRESS}

Employment and income expectations and concerns are traditionally of more importance to men $(2,13,14)$. In Western cultures, men are expected to provide for their families. For men, it is more difficult to lose a social and economic status than for women. The widespread youth unemployment in many countries worldwide may have particularly negative impact upon young men (15). This needs to be studied in the context of stress reduction to prevent depression and suicide and to preserve function to help unemployed men to find new jobs.

\section{BEREAVEMENT}

The process of bereavement after widowhood may be more difficult for husbands $(16,17)$, though recent data suggests many complex factors may underlie earlier evidence that supported this claim (18). As researchers and clinicians, we must explore the particular factors, which may make bereavement more difficult, and we must ask what kind of psychotherapy can be performed that may specifically target male vulnerability to complications of bereavement.

\section{HORMONES}

Testosterone levels in adults have been directly linked to impulsivity, aggression, desire to dominate, depression, and criminality $(19,20)$. Testosterone may produce this effect via organizational and activational effects. Organizational effects refer to the effects which testosterone produces on the developing central nervous system during pregnancy and adolescence, whereas activational effects refer to those which serum testosterone levels directly produce. Clinical and research work must define and develop the understanding of both these pathways. 


\section{PHARMACOKINETICS}

Male and female sex hormones exert divergent effects upon the cytochrome P450 system and other metabolic enzymes (21, 22). Female hormones are inhibitors of CYP1A2, and smoking, a CYP1A2 inducer, is usually more frequent in men. Males, thus, on average, have greater CYP1A2 activity than females and may need higher doses of some psychiatric medications, including clozapine. There is more need for research in these gendered pharmacokinetic differences that, once wellestablished, need to be incorporated by clinicians in their work.

\section{SOCIAL AWARENESS}

There should be an increased public health awareness of differences in behavior and mental health between men and women. Public health interventions including education and primary preventative efforts focused on men are needed.

Men's mental health needs more attention from clinicians, researchers, and health policy makers. This declaration serves as a preliminary communication of the World Federation of Biological Psychiatry's Task Force on Men's Mental Health concerning future directions for research, clinical care, and public health policy.

\section{REFERENCES}

1. Rutz W, Rihmer Z. Suicidality in men - practical issues, challenges, solutions. J Mens Health Gend (2000) 4:393-401. doi:10.1016/j.jmhg.2007.07.046

2. Möller-Leimkühler AM. The gender gap in suicide and premature death or: why are men so vulnerable? Eur Arch Psychiatry Clin Neurosci (2003) 253:1-8. doi:10.1007/s00406-003-0397-6

3. Adams SH, Newacheck PW, Park MJ, Brindis CD, Irwin CE. Health insurance across vulnerable ages: patterns and disparities from adolescence to the early 30s. Pediatrics (2007) 119:e1033-9. doi:10. 1542/peds.2006-1730

4. Marcell AV, Ford CA, Pleck JH, Sonenstein FL. Masculine beliefs, parental communication, and male adolescents' health care use. Pediatrics (2007) 119:e966-75. doi:10.1542/peds.2006-1683
5. Vogel DL, Heimerdinger-Edwards SR, Hammer JH, Hubbard A. Boys don't cry: examination of the links between endorsement of masculine norms, self-stigma, and help-seeking attitudes for men from diverse backgrounds. J Couns Psychol (2011) 58:368-82. doi:10.1037/a0023688

6. Archer J. Sex differences in aggression in real-world settings: a meta-analytic review. Rev Gen Psychol (2004) 8:291-322. doi:10.1037/1089-2680.8.4.291

7. Strüber D, Lück M, Roth G. Sex, aggression and impulse control: an integrative account. Neurocase (2008) 14:93-121. doi:10.1080/13554790801992743

8. Gvion Y, Apter A. Aggression, impulsivity, and suicide behavior: a review of the literature. Arch Suicide Res (2011) 15:93-112. doi:10.1080/13811118. 2011.565265

9. Perry JL, Carroll ME. The role of impulsive behavior in drug abuse. Psychopharmacology (Berl) (2008) 200:1-26. doi:10.1007/s00213-008-1173-0

10. Sánchez-Martín JR, Azurmendi A, PascualSagastizabal E, Cardas J, Braza F, Braza P, et al. Androgen levels and anger and impulsivity measures as predictors of physical, verbal and indirect aggression in boys and girls. Psychoneuroendocrinology (2011) 36:750-60. doi:10.1016/j. psyneuen.2010.10.011

11. Meyer-Lindenberg A, Buckholtz JW, Kolachana B, R Hariri A, Pezawas L, Blasi G, et al. Neural mechanisms of genetic risk for impulsivity and violence in humans. Proc Natl Acad Sci U S A (2006) 103:6269-74. doi:10.1073/pnas.0511311103

12. Substance Abuse and Mental Health Services Administration. Addressing the specific behavioral health needs of men. Treatment Improvement Protocol (TIP) Series 56. HHS Publication No. (SMA) 13-4736. Rockville, MD: Substance Abuse and Mental Health Services Administration. (2013). p.1-245.

13. Stansfeld S, Candy B. Psychosocial work environment and mental health - a meta-analytic review. Scand J Work Environ Health (2006) 32:443-62. doi:10.5271/sjweh. 1050

14. Sher L. Per capita income is related to suicide rates in men but not in women. J Mens Health Gend (2006) 3:39-42. doi:10.1371/journal.pone. 0098405

15. Hammarström A. Health consequences of youth unemployment - review from a gender perspective. Soc Sci Med (1994) 38:699-709. doi:10.1016/ 0277-9536(94)90460-X

16. Bowling A, Windsor J. Death after widow(er)hood: an analysis of mortality rates up to 13 years after bereavement. Omega (1995) 31:35-49. doi: 10.1093/ageing/afp108
17. Stroebe MS. The broken heart phenomenon: an examination of the mortality of bereavement. $J$ Community Appl Soc Psychol (1994) 4:47-61. doi: 10.1002/casp. 2450040110

18. Sasson I, Umberson DJ. Widowhood and depression: new light on gender differences, selection, and psychological adjustment. J Gerontol B Psychol Sci Soc Sci (2014) 69:135-45. doi:10.1093/geronb/ gbt058

19. Mehta PH, Beer J. Neural mechanisms of the testosterone-aggression relation: the role of orbitofrontal cortex. J Cogn Neurosci (2010) 22:2357-68. doi:10.1162/jocn.2009.21389

20. Mazur A. The role of testosterone in male dominance contests that turn violent. Soc Biol (2006) 53:24-9. doi:10.1080/19485565.2006.9989114

21. Parkinson A, Mudra DR, Johnson C, Dwyer A, Carroll KM. The effects of gender, age, ethnicity, and liver cirrhosis on cytochrome P450 enzyme activity in human liver microsomes and inducibility in cultured human hepatocytes. Toxicol Appl Pharmacol (2004) 199:193-209. doi:10.1016/j.taap.2004. 01.010

22. Rodenburg EM, Eijgelsheim M, Geleijnse JM, Amin N, van Duijn CM, Hofman A, et al. CYP1A2 and coffee intake and the modifying effect of sex, age, and smoking. Am J Clin Nutr (2012) 96:182-7. doi:10.3945/ajen.111.027102

Conflict of Interest Statement: The authors declare that the research was conducted in the absence of any commercial or financial relationships that could be construed as a potential conflict of interest.

Received: 17 October 2014; accepted: 03 November 2014; published online: 19 November 2014.

Citation: Sher L, Rihmer Z, Didia-Attas J, de Leon J, Lin $S$-K, Roncero C, Szerman $N$ and Rice $T$ (2014) Future research and clinical directions in the field of men's mental health: the Madrid declaration. Front. Public Health 2:242. doi: 10.3389/fpubh.2014.00242

This article was submitted to Child Health and Human Development, a section of the journal Frontiers in Public Health.

Copyright (C) 2014 Sher, Rihmer, Didia-Attas, de Leon, Lin, Roncero, Szerman and Rice. This is an open-access article distributed under the terms of the Creative Commons Attribution License (CC BY). The use, distribution or reproduction in other forums is permitted, provided the original author(s) or licensor are credited and that the original publication in this journal is cited, in accordance with accepted academic practice. No use, distribution or reproduction is permitted which does not comply with these terms. 